\section{Consultant manpower}

Sir: The College is undoubtedly aware of the severe shortage of properly trained applicants for permanent consultant posts. While the effort to expand senior registrar numbers by way of JPAC must continue there may be initiatives the College could take short of this which could increase the supply of appointable candidates. This has become clear to me as I have tapped the reservoir of consultant post applicants. A significant number of these fall just short of being appointable to permanent posts, usually for one or both of two reasons.

First, high quality foreign graduates enter the country on a Postgraduate Doctors Visa which allows only four years postgraduate medical training. These graduates complete their MCRPsych but the expiry of their visas prevents enrolment in higher training and they are forced to take non-training posts in order to obtain a work permit. Although the visa can be extended this occurs only rarely in practice. As a consequence there is a significant wastage of partly trained high quality trainees. Perhaps the College could campaign for a change for the length of visas, or for greater ease in its extension, in recognition of the shortage of qualified trainees. This strategy would have the attraction for the government of being broadly resource neutral.

Second, some psychiatrists have 'abnormal' CVs (for instance have postponed training for family reasons) or have found clinical assistant or even locum consultant jobs in the past without higher training. These doctors are not appointable to permanent posts despite the fact that they are actually providing the service in many hospitals and cannot then, strictly speaking, be appointed as locums. Yet some of these doctors could be brought to the correct standard by a perhaps curtailed period of higher training. Such an initiative would require agreement about assessing the abilities of these doctors, a commitment from higher training schemes to offer places to such doctors, and perhaps some sort of College authorised 'clinic' for the assessment, counselling and perhaps placing of these doctors.
A proposal of this sort will be resisted as lowering standards or as being politically impossible but the fact is that at present many consultant posts are filled by locum doctors, who by the College's present regulations, are inadequately trained. Further, the manpower problem is not going to go away - JPAC's assumptions for consultant growth (Allen, 1993) were for 120 posts at September 1993 while the number of consultant posts advertised from November 1993 to October 1994 was 251 (Wilson \& Allen, 1994)!

ALLEN, P. (1993) Medical and dental staff and prospects in the NHS in England and Wales in 1992. Health Trends, 25. 188-126.

Wrison, R. \& ALLEN, P. (1994) Medical and dental staff and prospects in the NHS in England and Wales in 1993. Health Trends, 26, 70-79.

PETER JARRETT, Greenwich Healthcare, Greenwich District Hospital, London SE1O 9HE

Sir: The problem is undoubtedly substantial. At least one College Division has more than $\mathbf{5 0}$ vacant consultant posts.

The College has successfully negotiated substantial increases in senior registrar manpower quotas in recent years but these increases have not been fully funded. This has led to the frustrating situation of large numbers of qualified applicants unable to obtain senior registrar posts but insufficient applicants for consultant posts.

Dr Jarrett makes two suggestions, both of which have been considered by the Manpower Committee.

The first lies outside the control of the College and would require a major change in Home Office regulations. Many visiting registrars are of high quality and some would like to stay in the United Kingdom or Ireland. However they have overseas sponsors who recommend them for training so that they may return to their own countries to enhance mental health services. It could be argued that any attempt by the College to lobby for a change in regulations to allow such doctors to remain on a long-term basis would be a breach of the agreement with their sponsors. 